\title{
Factors predicting patient satisfaction in the emergency department: a single-center study
}

\author{
Somaye Younesian ${ }^{1}$, Reza Shirvani ${ }^{2}$, Ali Tabatabaey ${ }^{3 *}$ \\ 'Department of Emergency Medicine, Ayatollah Kashani Hospital, Tehran, Iran \\ 2Department of Emergency Medicine, Nekoee-Hedayati Hospital, Qom University of Medical Sciences, Qom, Iran \\ ${ }^{3}$ Department of Emergency Medicine, Shahid Beheshti Hospital, Qom University of Medical Sciences, Qom, Iran
}

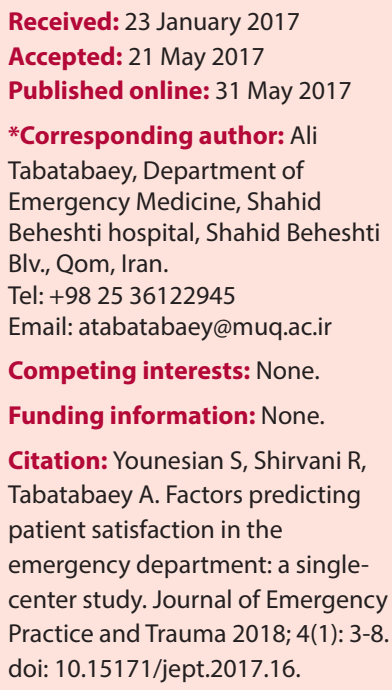

\begin{abstract}
Objective: Patient satisfaction (PS) is a major quality assessment index for the emergency department (ED) which affects patient safety, litigation, reimbursements, and consumer satisfaction. In this study we aimed to recognize the factors affecting PS in our center. Methods: Random shifts during a week were selected and all patients disposed from the ED were asked to fill out a revised and validated Persian version of the Press-Ganey questionnaire with the help of a research assistant. Results were analyzed using a linear regression model by SPSS software version 21 .

Results: Findings reaffirmed some of the factors previously described. These included longer door to treatment area times having a negative effect on satisfaction $(P<0.001)$, and providing vivid discharge information improving PS $(P<0.001)$. Other important factors were also found that had not previously been focused on, namely cleanliness of the area $(P<0.0001)$ and courtesy of the staff in charge of patient transfer $(P=0.03)$. We also found that men had a more satisfying ED experience $(P=0.002)$.

Conclusion: Cultural expectations may have an important effect on PS. Thus, every institution should determine and alter the expectations most relevant to them. Keywords: Emergency department, Patient satisfaction, Waiting times, Gender
\end{abstract}

\section{Introduction}

Patient satisfaction (PS) is the ultimate goal of any medical institute. Evidence shows that satisfied patients are more compliant with their treatments and are more likely to return for future care (1). The primary goal of caregivers should be providing quality care; and PS is not always in line with quality care. Nonetheless, PS determines many outcomes that are important to physicians and managers alike, which make it an important goal for all. There is an ongoing debate over the relationship between clinical outcomes and indices of PS $(2,3)$. Regardless of this debate, such indicators have been incorporated into the assessment and reimbursement processes of emergency departments (EDs). Therefore, many management decisions aim to improve these indices. Moreover, PS surveys allow insurance companies and health ministries to evaluate physicians, while consumer-oriented Web sites often report PS scores and influence consumer choice $(2,4)$.

In the ED, achieving PS is very difficult. The encounter between caregivers and patients in the ED is often complicated by many factors. These complexities often lead to a discrepancy between quality service, as perceived by caregivers, and PS $(4,5)$. In the ED, time and resources are often limited and caregivers cannot fulfill the patients' discretionary needs just to improve their satisfaction. Therefore, a comprehensive consideration of the factors predicting PS can help us make improvements. Often, the perception and interpretation of satisfaction is closely related to the cultural and socio-economic context and the strategies needed for its improvement are not universal. In this study, we aimed to assess patients' satisfaction in the ED of a major trauma center in the city of Qom in Iran.

\section{Methods}

This cross-sectional study was designed to assess the factors affecting PS in Nekoee hospital, a regional trauma center in Qom, Iran. Samples were collected randomly from different shifts during a one week period in the summer of 2015. All patients disposed from the emergency department during each shift were included in the study. Patients were excluded if they were unable to answer questions (significant cognitive impairment, were unable to communicate in Farsi) or were unwilling to participate. The questionnaires were completed prior to disposition from the ED. The patients or their designated relatives were introduced to the study by a member of the research team which was not involved in the patient's treatment 
and was not wearing a uniform. It was explained that participation in the study would not have any effect on the care provided to the patients. Patients or relatives were asked to fill out the form in a safe environment without the presence of the treatment staff. In case of any assistance in filling out the form (illiteracy, physical limitations, etc), an interviewer helped accordingly.

The questionnaire used in our study was a modified version of Press Ganey survey. This instrument is both reliable and valid within the Iranian population (6). The questionnaire was slightly revised to improve coherency and items like number of visits and waiting times were expressed in actual numbers rather than Likert scales. The validity of the final questionnaire was obtained by emergency physicians and tested in a pilot study with 50 patients. The final questionnaire included three main sections. The first section encompassed demographic information such as the time of admission categorized by work shift intervals, sex, age, educational level, place of residence, type of admission, and being a local resident or a traveler. The second section included questions regarding the length of stay before going to an exam room, amount of time the doctor spent with patient, and frequency of visits by a physician. The third section included questions about comfort of the waiting area, courtesy of nurses, nursing skills, courtesy of security staff, respect to patients' privacy during examination, courtesy of staff who transfer the patients, friendliness/courtesy of the physicians, doctors explanations to patients about the disease and their conditions, concerns that care provider showed for patients' questions or worries, involving patients in decision making for their treatment, patient education before disposition, overall satisfaction, and the possibility of recommending the ED of this center to others. Participants were asked to answer the statements on a Likert scale ranging from 1 (very poor) to 5 (very good).

Data were analyzed using SPSS software version 21. For continuous variables we used mean and standard deviation. Concerning discrete variables, frequency and mode were applied accordingly. The score of patients' overall satisfaction and the willingness to recommend the ED to others were considered as the primary outcomes. Using a forward linear regression model, the effects of demographic variables and different items of the questionnaire on these two outcomes were analyzed. A $P$ value less than 0.05 was considered significant. The study was reviewed and approved by the research and ethic center of Qom University of Medical Sciences.

\section{Results}

Overall 499 patients were included in the study. Over 60\% were male and almost half of the patients had previously attended the hospital. Most patients had arrived during the evening hours and only $5.6 \%$ had arrived during the night shift. Most of the participants had high school education. Almost $90 \%$ of the participants were residents of Qom. Nineteen to 35 year olds were the most common group of patients. This was closely followed by pediatric patients under the age of 18 . About $80 \%$ of the patients were discharged from the ED, while $4(0.8 \%)$ left the ED against medical advice. Table 1 summarizes the demographics of the participants.

All items answered on the Likert scale either received good (speed of registration, condition of the waiting area, information provided by caregiver) or very good ratings. More information is provided in Table 2. The mean time between triage and arriving at the treatment area was $60.7 \pm 95.6$ minutes. The average time from arrival to the treatment area until physician's visit was $9.4 \pm 22.8$ minutes. The mean time spent by the physician with patients was $7.3 \pm 3.8$ and the average number of visits was $2.0 \pm 0.8$. Regarding the suggestion of the ED to others, $36.5 \%$ answered very likely and $35.7 \%$ answered likely.

Findings showed that factors contributing to patients' overall satisfaction of the ED services were cleanliness of the area, information provided by the physician on follow-

Table 1. Demographic distribution of participants ${ }^{\mathrm{a}}$

\begin{tabular}{|c|c|c|}
\hline & Number & Percent \\
\hline \multicolumn{3}{|l|}{ Person answering } \\
\hline Self & 263 & 52.7 \\
\hline Relative & 236 & 47.3 \\
\hline \multicolumn{3}{|l|}{ Time of attendance } \\
\hline Morning & 175 & 35.1 \\
\hline Evening & 296 & 59.3 \\
\hline Night & 28 & 5.6 \\
\hline \multicolumn{3}{|l|}{ History of previous attendance } \\
\hline Had previously attended our ED & 247 & 49.5 \\
\hline First time attending our ED & 252 & 50.5 \\
\hline \multicolumn{3}{|l|}{ Gender } \\
\hline Male & 301 & 60.3 \\
\hline Female & 198 & 39.7 \\
\hline \multicolumn{3}{|l|}{ Level of education } \\
\hline Primary & 85 & 17.0 \\
\hline Secondary & 219 & 43.9 \\
\hline University & 49 & 9.8 \\
\hline Other & 146 & 29.3 \\
\hline \multicolumn{3}{|l|}{ Place of residence } \\
\hline Qom & 443 & 88.8 \\
\hline Suburbs & 39 & 7.8 \\
\hline Other & 12 & 2.4 \\
\hline \multicolumn{3}{|l|}{ Age groups } \\
\hline Below 18 & 163 & 32.7 \\
\hline 19 to 35 & 197 & 39.5 \\
\hline 36 to 60 & 106 & 21.2 \\
\hline Over 60 & 33 & 6.6 \\
\hline \multicolumn{3}{|l|}{ Disposition } \\
\hline Discharged & 395 & 79.2 \\
\hline Admitted & 98 & 19.6 \\
\hline Transferred & 2 & 0.4 \\
\hline Leaving against medical advice & 4 & 0.8 \\
\hline
\end{tabular}

${ }^{a}$ Missing data not included. 
Table 2. Satisfaction with 16 items

\begin{tabular}{|c|c|c|c|c|c|}
\hline & Very poor & Poor & Fair & Good & Very good \\
\hline Speed of the registration process & 6.4 & 6.6 & 15.0 & 36.9 & 34.7 \\
\hline Courtesy of registration staff & 5.6 & 6.4 & 14.4 & 35.7 & 37.3 \\
\hline Comfort of the waiting area & 4.8 & 7.0 & 13.8 & 37.9 & 35.1 \\
\hline Attention to patient privacy & 4.6 & 7.0 & 13.4 & 36.1 & 37.3 \\
\hline Courtesy of the nursing staff & 4.2 & 6.8 & 12.8 & 36.5 & 37.7 \\
\hline Quality of nursing care & 4.4 & 6.6 & 14.2 & 34.9 & 36.3 \\
\hline Courtesy of the security staff & 4.8 & 6.8 & 12.6 & 35.1 & 36.9 \\
\hline Courtesy of staff who transfer patients & 4.8 & 6.6 & 11.8 & 34.9 & 37.9 \\
\hline Courtesy of the physician & 5.2 & 6.2 & 10.0 & 33.5 & 40.9 \\
\hline Physician's explanations & 5.0 & 6.4 & 11.4 & 34.5 & 38.3 \\
\hline Physician's response to questions & 5.4 & 6.2 & 9.8 & 34.5 & 37.5 \\
\hline Involving patients in treatment decisions & 5.0 & 7.8 & 10.8 & 33.1 & 33.3 \\
\hline Information provided about medication & 4.6 & 6.4 & 10.8 & 34.5 & 32.3 \\
\hline Information on follow up & 4.4 & 6.4 & 10.0 & 32.7 & 35.1 \\
\hline Overall satisfaction & 4.0 & 6.0 & 12.2 & 33.9 & 41.9 \\
\hline Satisfaction with cleanliness & 4.0 & 6.6 & 12.8 & 35.3 & 38.1 \\
\hline
\end{tabular}

up care, satisfaction with staff in charge of transferring patients, and a shorter time from triage to treatment area. The factors associated with a patient's willingness to recommend the ED to others were: satisfaction with cleanliness of the treatment area, satisfaction with speed of the registration process, satisfaction with staff in charge of transferring patients, a shorter wait from triage to treatment area, and male gender. We did not observe any relationship between other demographic data and the outcomes. Table 3 shows the results of the linear regression analysis.

\section{Discussion}

There are many reasons to consider PS as a primary goal in the ED. Satisfied patients are more likely to comply with treatment, thus, their well-being will improve. Satisfied patients are also less likely to claim liability. Furthermore, financial reimbursements and future return of "consumers" depend on PS (1). Iran enjoys subsidized global healthcare but still administrators and researchers look at PS as an indicator of success in a medical institute (6-11). Our study found that the cleanliness of ED was a significant predictor of both overall satisfaction and patient's willingness to suggest ED to others. By the same token, the courtesy of staff transferring patients indicated that the non-medical aspects of patient care play a significant role in the satisfaction of patients. Moreover, two time-related factors (speed of the registration process and time from triage to treatment area) were shown to be significant predictors of PS in our study. This shows that processing times before patients initially receive treatment are key to their satisfaction. Last but not least doctor-patient interactions, as presented by the doctor's willingness to offer follow-up information, had an undeniable effect on overall satisfaction of patients.

Early studies by Sun et al identified six factors in the

Table 3. Factors influencing outcomes based on linear regression analysis

\begin{tabular}{|c|c|c|c|c|c|c|}
\hline Outcomes & Factors influencing outcome & B & SE & $\begin{array}{c}\text { Standardized } \\
\text { Coefficients (Beta) }\end{array}$ & $\boldsymbol{t}$ & $P$ \\
\hline \multirow{4}{*}{$\begin{array}{l}\text { Overall } \\
\text { satisfaction }\end{array}$} & Satisfaction with ED cleanliness & 0.392 & 0.068 & 0.390 & 5.782 & 0.000 \\
\hline & Satisfaction with staff in charge of patient transfers & 0.311 & 0.058 & 0.327 & 5.379 & 0.000 \\
\hline & Satisfaction with information provided about follow-up & 0.149 & 0.044 & 0.190 & 3.384 & 0.001 \\
\hline & Duration of time from entrance to treatment area & -0.001 & 0.001 & -0.095 & -2.112 & 0.036 \\
\hline \multirow{5}{*}{$\begin{array}{l}\text { Tendency to } \\
\text { suggest the ED } \\
\text { to others }\end{array}$} & Satisfaction with ED cleanliness & 0.728 & 0.056 & 0.659 & 12.889 & 0.000 \\
\hline & Satisfaction with speed of the registration process & 0.179 & 0.061 & 0.153 & 2.944 & 0.004 \\
\hline & Duration of time from entrance to treatment area & -0.002 & 0.001 & -0.123 & -3.475 & 0.001 \\
\hline & Gender & -0.311 & 0.098 & -0.111 & -3.187 & 0.002 \\
\hline & Satisfaction with staff in charge of patient transfers & 0.121 & 0.055 & 0.117 & 2.225 & 0.027 \\
\hline
\end{tabular}

Abbreviations: ED, emergency department; SE, standard error. 
ED associated with poor satisfaction. They included not receiving help when needed, poor explanation about the problem or test results, lack of information on waiting times, time to resume normal activities, and not understanding when to return to the $\operatorname{ED}(12,13)$. Boudreaux and O'Hea conducted a systematic review on PS in the ED in 2004 (1). They found interpersonal interactions with ED providers to be the most strongly associated factor with overall PS in the ED. Interpersonal interactions were classified as either expressive quality (i.e. the ability of the caregiver to show empathy and demonstrate proper courtesy) or information delivery (i.e. the willingness and ability of staff to provide information regarding the care process). The authors also pointed to few studies where doctors' and nurses' technical skillfulness were the primary contributor to PS (14), but they stated that from a patient's perspective, caregivers who had better interpersonal skills were considered as more skillful. Boquiren et al found that patient's satisfaction with the doctor is the most important aspect of care. The authors named five domains as determinants of PS with a doctor: Communication Attributes, Relational Conduct, Technical Skill and Knowledge, Personal Qualities, Availability and Accessibility. They also proposed that a physician's training should focus on these domains (15). The review by Taylor and Benger points out two service factors in this domain that seem to affect PS. They are: interpersonal skills and perceived staff attitudes, provision of information and explanation (16). In our study we found two factors of this sort which had an effect on PS. They included doctors' dedication to provide follow up information to patients, and the courtesy of the staff in charge of patient transfers. We also found logistic factors such as cleanliness and speed of the registration process as important factors.

Boudreaux and O'Hea did not find any association between gender, marital status, insurance status, presence of pain, number of previous ED visits, time/day of arrival, satisfaction with registration and other demographic variables with the overall satisfaction of patients (1). Conversely, we found gender and courtesy of the staff transferring patients as important factors. Gender has rarely been recognized as a significant variable affecting PS in the ED. It has been noted that female patients are more likely to respond to PS questionnaires (17) and the role of gender in settings other than ED has been suggested $(18,19)$. Zohrevandi and Tajik also recognized that female patients were more satisfied (11), a finding that was replicated by Reihani et al (9), Son and Yom (20), and Abolfotouh et al (21). This may be due to the fact that females are more tolerant. In our study, on the other hand, female gender was significantly associated with less satisfaction. This can be related to different expectations of women in a highly religious environment like Qom which cannot be met in the ED setting. Moreover, we believe that the effect attributed to the staff in charge of transferring patients may have two reasons. First, these staff spend a longer time with patients compared to other caregivers.
Second, they are involved in an intimate and physical act of helping patients which is more obvious than the efforts of other staff members. It appears that in our setting, if this aspect of care is done with courtesy and respect, it may be a source of gratitude and satisfaction.

Time-oriented indicators have been introduced as influential factors in PS. This study found the speed of registration and time from triage to arrival at the treatment area as significant factors in predicting outcomes. Welch proposes that time from entering the ED until a visit made by the physician is the most important duration in PS (4). Other studies have reported similar findings in which the time elapsed from arrival and triage to a visit by the physician is a major determinant of satisfaction $(6,22)$. In other words, longer wait times lead to dissatisfaction $(21,23)$. Yet, in a study performed by Arab and colleagues in Tehran EDs, no significant correlation was found between time-to-provider, left-without-treatment and length-of-stay time variables and overall PS (7). It has been suggested that aspects related to waiting times, particularly perceived waiting time, is a predictor of PS (16). In our study we found the speed of registration to be an important item. This is obviously due to the fact that patients prefer to be attended as soon as possible and see any paper work as unnecessary. This may be fueled by the perception that a faster registration process may lead to a faster visit by the physician. Triage level, another frequently reported predictor of PS, may actually be a reflection of shorter waiting times for sicker patients (16). Factors that have previously been shown to affect PS are not limited to those discussed here. Zohrevandi and Tajik reported a correlation between PS and the time of admission (11). In a separate study Damghi et al named the following 3 items as independent variables predictive of less satisfaction: living distance from the hospital, admission during weekdays and level of education (24). Soleimanpour et al also reported that higher education was correlated with more dissatisfaction (6). Several studies have noted that older patients are more likely to be satisfied with the care they receive $(9,20,22,25)$. Another interesting factor recorded by Abolfotouh et al was symptom improvement as reported by the patient (21). Pines et al also reported a robust association between indicators of ED overcrowding and lower PS scores (23). In our study we did not find any relationship between main outcomes and most demographic data. This is in line with previous studies $(1,16)$. The demographic data in our study included patients' place of residence, education level, age, gender, and the time of day attending the ED. None of these variables were found to affect our main outcomes except for gender. This shows that many variables which affect PS in the ED are the ones which can be altered and improved.

\section{Conclusion}

Factors affecting PS are numerous. Some of these factors even contradict what caregivers see as best clinical practice. Therefore, one must admit that patients are not the best 
assessors of clinical quality (26). Nonetheless, achieving PS has many merits that make it one of the top goals of any medical institute. Literature has revealed many factors associated with PS. These range from bedside manner and empathy to physician gender and attire, acceptable wait times, technical skills, pain management, use of bedside ultrasonography, privacy, cleanliness, and safety (4). Some factors are hard to change but others may be easily altered to improve satisfaction. Fortunately, interventions have been effective accordingly (17,27-29). For some institutions depending on the population they serve, some of these factors may be more important than others. In our center we found that the factors most closely related to PS may be logistic (cleanliness), staff-related (courtesy of transferring staff), process related (speed of registration process), and physician-related (providing information on follow up).

\section{Limitations}

There are several limitations to our study. Because we used a previously validated questionnaire, we were unable to assess all factors that may have an effect on PS. As we wanted to pool and compare the results of different studies, we did not expand the items of the questionnaire. Still the external validity of our study may be limited because of the unique characteristics of the study population. Overall, each ED should take its own predictors of satisfaction into consideration and devise a plan to address the shortcomings in the most practical manner. In our study we recognized the factors most relevant to our institution. As with other satisfaction studies; generalization of these results must be considered with caution.

\section{Ethical issues}

The study was approved by the ethical committee at Qom University of Medical Sciences.

\section{Author's contribution}

All authors contributed to the study concept, design, data gathering, and manuscript preparation. Doctor Tabatabaey also contributed in data analysis.

\section{References}

1. Boudreaux ED, O'Hea EL. Patient satisfaction in the Emergency Department: a review of the literature and implications for practice. J Emerg Med 2004; 26(1): 13-26. doi: 10.1016/j.jemermed.2003.04.003.

2. Fenton JJ, Jerant AF, Bertakis KD, Franks P. The cost of satisfaction: a national study of patient satisfaction, health care utilization, expenditures, and mortality. Arch Intern Med 2012; 172(5): 405-11. doi: 10.1001/ archinternmed.2011.1662.

3. Friedberg MW, Gelb Safran D, Schneider EC. Satisfied to death: a spurious result? Arch Intern Med 2012; 172(14): 1112-3. doi: 10.1001/archinternmed.2012.2060.

4. Welch SJ. Twenty years of patient satisfaction research applied to the emergency department: a qualitative review. Am J Med Qual 2010; 25(1): 64-72. doi: $10.1177 / 1062860609352536$.
5. Johansen ML. Conflicting priorities: emergency nurses perceived disconnect between patient satisfaction and the delivery of quality patient care. J Emerg Nurs 2014; 40(1): 13-9. doi: 10.1016/j.jen.2012.04.013.

6. Soleimanpour H, Gholipouri C, Salarilak S, Raoufi P, Vahidi RG, Rouhi AJ, et al. Emergency department patient satisfaction survey in Imam Reza Hospital, Tabriz, Iran. Int J Emerg Med 2011; 4: 2. doi: 10.1186/1865-1380-1-2.

7. Arab M, Movahed Kor E, Mahmoodi M. The effect of time-to-provider, left-without-treatment and length-ofstay on patient satisfaction in training hospitals' emergency department, Iran. Iran J Public Health 2015; 44(10): 1411-7.

8. Atari M, Atari M. Brief Emergency Department Patient Satisfaction Scale (BEPSS); development of a new practical instrument. Emerg (Tehran) 2015; 3(3): 103-8.

9. Reihani H, Pishbin E, Abbasi Shaye Z, Ebrahimi M, Bolvardi E, Talebi Delooi M, et al. Patient satisfaction analysis in emergency department in Imam Reza hospital of Mashhad. Patient Saf Qual Improv 2015; 3(1): 179-83.

10. Taghizadeh $\mathrm{H}$, Taghizadeh $\mathrm{F}$. The comparing of health cares's satisfaction in main and satellite villages of Qom province, Iran. Adv in Biol Res 2013; 7(6): 305-9. doi: 10.5829/idosi.abr.2013.7.6.11191.

11. Zohrevandi B, Tajik H. A survey of patients' satisfaction in emergency department of Rasht Poursina hospital. Emerg (Tehran) 2014; 2(4): 162-5.

12. Sun BC, Adams J, Orav EJ, Rucker DW, Brennan TA, Burstin HR. Determinants of patient satisfaction and willingness to return with emergency care. Ann Emerg Med 2000; 35(5): 426-34. doi: 10.1067/mem.2000.104195.

13. Sun BC, Adams JG, Burstin HR. Validating a model of patient satisfaction with emergency care. Ann Emerg Med 2001; 38(5): 527-32. doi: 10.1067/mem.2001.119250.

14. Rhee KJ, Bird J. Perceptions and satisfaction with emergency department care. J Emerg Med 1996; 14(6): 67983. doi:10.1016/S0736-4679(96)00176-X.

15. Boquiren VM, Hack TF, Beaver K, Williamson S. What do measures of patient satisfaction with the doctor tell us? Patient Educ Couns 2015; 98(12): 1465-73. doi: 10.1016/j. pec.2015.05.020.

16. Taylor C, Benger JR. Patient satisfaction in emergency medicine. Emerg Med J 2004; 21(5): 528-32. doi: 10.1136/ emj.2002.003723.

17. Taylor D, Kennedy MP, Virtue E, McDonald G. A multifaceted intervention improves patient satisfaction and perceptions of emergency department care. Int J Qual Health Care 2006; 18(3): 238-45. doi: 10.1093/intqho/ mzl002.

18. Hargraves JL, Wilson IB, Zaslavsky A, James C, Walker JD, Rogers G, et al. Adjusting for patient characteristics when analyzing reports from patients about hospital care. Med Care 2001; 39(6): 635-41.

19. McKinley RK, Stevenson K, Adams S, Manku-Scott TK. Meeting patient expectations of care: the major determinant of satisfaction with out-of-hours primary medical care? Fam Pract 2002; 19(4): 333-8. doi: 10.1093/fampra/19.4.333.

20. Son H, Yom YH. Factors influencing satisfaction with emergency department medical service: patients' and their companions' perspectives. Jpn J Nurs Sci 2017; 14(1): 27-37. doi: 10.1111/jjns.12132.

21. Abolfotouh MA, Al-Assiri MH, Alshahrani RT, Almutairi ZM, Hijazi RA, Alaskar AS. Predictors of patient satisfaction in an emergency care centre in central Saudi Arabia: a 
prospective study. Emerg Med J 2017; 34(1): 27-33. doi: 10.1136/emermed-2015-204954

22. Morgan MW, Salzman JG, LeFevere RC, Thomas AJ, Isenberger KM. Demographic, operational, and healthcare utilization factors associated with emergency department patient satisfaction. West J Emerg Med 2015; 16(4): 516-26. doi: 10.5811/westjem.2015.4.25074.

23. Pines JM, Iyer S, Disbot M, Hollander JE, Shofer FS, Datner EM. The effect of emergency department crowding on patient satisfaction for admitted patients. Acad Emerg Med 2008;8;15(9):825-31. doi: 10.1111/j.15532712.2008.00200.x.

24. Damghi N, Belayachi J, Armel B, Zekraoui A, Madani N, Abidi K, et al. Patient satisfaction in a Moroccan emergency department. Int Arch Med 2013; 6: 20. doi: 10.1186/17557682-6-20.

25. Davis BA, Duffy E. Patient satisfaction with nursing care in a rural and an urban emergency department. Aust J Rural Health 1999; 7(2): 97-103. doi: 10.1046/j.1440- 1584.1999.00231.x.

26. Cowan P. Press Ganey scores and patient satisfaction in the emergency department (ED): the patient perspective. Pain Med 2013; 14(7): 969. doi: 10.1111/pme.12170_3.

27. Chandra A, Sieck S, Hocker M, Gerardo CJ, Villani J, Harrison D, et al. An observation unit may help improve an institution's Press Ganey satisfaction score. Crit Pathw Cardiol 2011; 10(2): 104-6. doi: 10.1097/ HPC.0b013e31821c5da8.

28. Zakerimoghadam M, Sadeghi S, Ghiyasvandian S, Kazemnejad A. The effect of trauma intervention on the satisfaction of patients admitted to the emergency department: a clinical trial study. Iran Red Crescent Med J 2016; 18(4): e26452. doi: 10.5812/ircmj.26452.

29. Hwang CE, Lipman GS, Kane M. Effect of an emergency department fast track on Press-Ganey patient satisfaction scores. West J Emerg Med 2015; 16(1): 34-8. doi: 10.5811/ westjem.2014.11.21768. 